\title{
(0005) Practical possibilities of pumped-storage power plants implementation in liquidated underground mines.
}

\author{
1st author (corresponding author) ${ }^{1 凶}$, 2nd author ${ }^{1}$, and 3rd author ${ }^{2}$ \\ ${ }^{1}$ Universiti ..., 00000 City, State if any, Country, \\ ${ }^{2}$ Universiti ..., 00000 City, State if any, Country, \\ $\otimes_{\text {author.email@gmail.com }}$
}

\begin{abstract}
In the paper the theoretical basis of pumped-storage power plant operation is presented. Working conditions of hydraulic machines in these kinds of objects are described and examples are given. The Czech research results as well as German theoretical analyses on the topic of water energy storage in underground mines are characterized. The conditions for building pumped-storage power plant in Polish underground coal mines, including liquidated ones, are determined. Analysis of parallel operation of multistage centrifugal pumps, dedicated to the mine drainage system, manufactured and operated commonly in Poland is presented. The main dimensions calculations of two multistage centrifugal pumps (power of $10 \mathrm{MW}$ and 25 $\mathrm{MW}$ ), dedicated for selected parameters, are presented.
\end{abstract}

Keywords: pumped-storage power plant ,liquidated mine, pump, water turbine, energy storage

\section{Introduction}

The recent development of renewable energy sources (RES) raise a problem of power shortages in the power grid in periods of decline in generation from RES, that need to be quickly replenished [1][2]. This problem concerns especially wind and solar energy. Currently, high power accumulation is realized through pumpedstorage power plants, chemical lead-acid and sodiumsulphur batteries or compressed air installations [3].

Intensive work is under way on energy production by means of electrolysis of hydrogen, as well as its storage and further use. Research and trials of energy accumulation are being carried out in directions which were considered expensive and technically difficult to implement so far, e.g. accumulation and production of electricity in the form of heat. At the same time, the developed production of large chemical batteries revealed their weakness: the cells' susceptibility to short circuits, self-ignition and burning. In the past, the development and the number of commissioned pumped-storage power plants was associated with the development of nuclear power plants, operating at a constant, optimal load.

Pumped-storage power plants are currently the largest and dominant energy storage in the world, accounting for approx. 95\% of the active electricity indirect accumulation installations. The common use of pumpedstorage power plants is related to its load balancing function in cooperation with nuclear power plants. A practically and commonly used method is pumping water to the upper reservoir during periods of surplus electricity production and its release through water turbines into the lower water tank. New high power installations can work with efficiency up to $75 \%$ and have very long service life [4].

The first pumped-storage power plant is considered to be the facility in Kubel, Switzerland, built by engineer Louis Kürsteinerměl. It supplied the paper mill by four machines with total power of 500 horsepower. The next pumped-storage power plant was a $5 \mathrm{MW}$ unit in Engeweiher, Switzerland. The level of electric power obtained from working units is predictable and have very short, several-minute period of inclusion in the power system, both in pumping and turbine mode. The parameter that determines the popularity of pumped-storage power plants is the energy density that can be accumulated in a unit of volumetric flow rate elevated to unit height. Other beneficial aspects are: wide availability of water, which does not lose its original properties after the work is done, and the relatively high operational safety of pumped-storage power plants, confirmed by years of experience.

In Fig.1 a classic pumped-storage power plant is presented. One reversible hydraulic machine is pumping water from the lower reservoir to the upper reservoir or generates power with water going in the opposite direction. Usually, the upper reservoirs are located on adapted mountains and hills, at the top of which regular pools are built, insulated from the ground and separated from the surrounding area. Lower reservoirs 


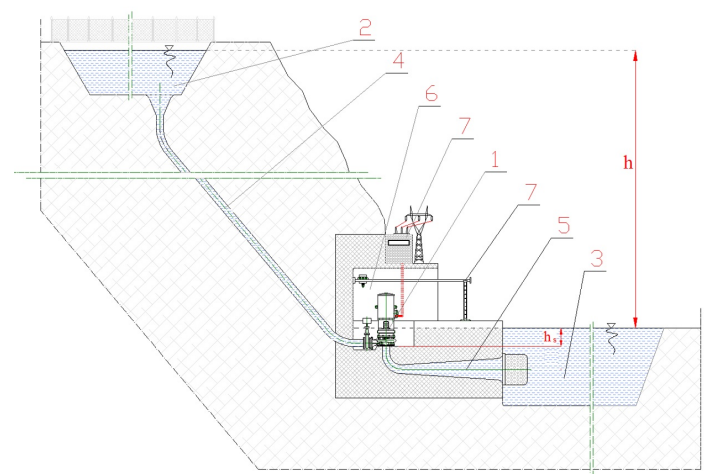

Figure 1: Pumped-storage power plant scheme. 1pump-turbine unit 2- upper reservoir 3-lower reservoir 4-intake tunnel 5- discharge tunnel 6-power-house 7transformers.

are not as demanding and are usually natural or modified catchments. The size of the upper reservoir and the system of water pumps and turbines technology determine the possible generation work period, usually lasting several hours per day. In the current energy system, based to a large extent on the production of electricity from fossil fuel combustion and nuclear energy, both the turbine operation time and the number of pumped-storage power plants in the territories of EU countries were practically sufficient. The lack of emissivity and low environmental impact was the reason for social acceptance for pumped-storage power plants. The possibility of using previously accumulated energy in water allowed for calm and planned management of electricity by the power systems operators. The power industry has been using these solutions since the early 1930s. The world potential of pumped-storage power plants is about $130 \mathrm{GW}$, of which $25 \mathrm{GW}$ in Japan, $22 \mathrm{GW}$ in the USA, $15 \mathrm{GW}$ in China, over $40 \mathrm{GW}$ in Europe, of which almost $9 \mathrm{GW}$ in Germany alone ([5] [6] [7]). The highest head of $1772.5 \mathrm{~m}$ is at the Kolbnitz facility near Kaprun, Austria, where a $4234 \mathrm{~m}$ long pipeline supplies a system of 7 Pelton-type turbines from the Reißeck reservoir. The power plant has power of $138 \mathrm{MW}$.

Due to the gradual divestment from hard coal mining, in particular in Upper Silesia region in Poland, the concept of using the liquidated underground infrastructure of mines for the needs of pumped-storage power plants was taken into further consideration. The idea is that the upper reservoir would be embedded in the ground near the present mine shafts. Lower reservoir construction would be realized at the bottom and there would be pipelines in the shafts connecting both reservoirs. Such a concept is not new, but its practical application on a large scale has not yet been realized.
Apart from a few research works (closed iron mine in New Jersey 1975 or Jeremenko mine, Ostrava 2015), which, however, did not go beyond the experimental research phase, the power plant was not built using the infrastructure of the closed deep mines [8]. European countries that not have natural resources of hydropower plants and are intensively developing renewable energy, in particular Germany, exploit and plan to build new, large pumped-storage power plants. Currently, advanced analytical work is underway by a scientific and industrial consortium in Germany, supported by the European Commission, aimed at developing a program for the implementation of a technical concept for pumped-storage power plants in the closed underground mines.

Another interesting topic is the use of energy of water pumped from natural underground reservoirs in order to filter it and then pour it back through a water turbine to these underground reservoirs. This concept was considered after the detection of chemical contamination of deep-sea drinking water resources in Silesia (Karchowice).

Currently, analytical research is being carried out on typical pumped-storage power plants opening in the area of coal opencast mines in Australia and the USA (Arizona).

\section{Power that can be obtained from water barrage}

The efficiency of pumped-storage power plants is defined as the ratio of the energy produced during turbine mode operation to the energy supplied in pumping operation in a constant, repetitive cycle of the power plant operation. It is determined by formula:

$\eta_{s p}=\frac{E_{w}}{E_{d}} \cdot 100 \%$

The theoretical (hydraulic) power accumulated in water is defined by formula:

$N_{u}=\gamma \cdot Q \cdot H, W$

The energy produced in a pumped-storage power plant is determined as follows:

$E_{u}=N_{u} \cdot t, W h$

The head is the difference between the water levels in the upper and lower reservoirs. It expresses potential energy. Natural watercourses run down to catchment areas and lose their potential energy. It is assumed to be equal to zero at the level of seas and oceans. Kinetic energy is related to the water velocity. When it is used for water turbines, the kinetic energy of the watercourse can be converted into potential energy (water column) using the Bernoulli equation:

$h=\frac{V_{s}^{2}-V_{t}^{2}}{2 g}, m$ 
(and Deriaz type pumps), for micro and pico heads

In case of flow through the pump fluid speed in the discharge channel is higher (occasionally the same) than in the suction channel, which results from the literature recommendations for the pumping systems construction. In the suction channel, energy losses increase with the square of the water velocity and they are minimized in order to avoid cavitation in the flow system of the hydraulic machine (pump-turbine unit). The assumed velocity of water inflow to the pump in the suction channel is $V_{s}=1,5 \div 2, \frac{m}{s}$ compared to the velocity in the discharge channel $V_{t}=2 \div 2,5, \frac{\mathrm{m}}{\mathrm{s}}$. These relationships allow for a quick assessment of the energy potential of watercourses. Further calculations of power plant operating parameters require hydraulic machines. It is particularly important to know the chosen hydraulic machine efficiency in both turbine and pump operation. Efficiency value is individual for each pump-turbine unit and it is presented in the form of graphs. Efficiency depends on capacity, rotational speed and the angle of the rotor blades and the guides. In practice, during preliminary calculations, efficiency is reduced to one, optimal value for turbine operation (efficiency of a turbine, transmission, generator, energy transformer, control automation) $\eta_{t}$ and one for pumping operation (efficiency of a pump, coupling, electric motor, transformer energy, control automation) $\eta_{p}$. With correctly designed channels, it is possible to assess the power generated by the turbine $N_{t}$ and the power necessary to fill the upper reservoir with water $N p$.

$N_{t}=\frac{\gamma \cdot Q \cdot H}{\eta_{t}}, W$

$N_{p}=\frac{\gamma \cdot Q \cdot H}{\eta_{p}}, W$

Assuming constant energy supply and receipt, it is necessary to work longer in pumping mode comparing to the turbine mode in order to bring system to its initial state. When pumping water into the upper tank and, as well, when emptying it, the system actually operates at variable head $\mathrm{H}$, because, unlike the variable water level in the upper tank, the water level in the lower tank practically does not change. This tank is usually larger.

Pumped-storage power plants in which pumpinggeneration process occurs with one reversible machine have lower efficiency than in the case of separating the pumping and generation functions into two machines: pump and turbine. It is due to differences in the optimal pump and turbine design for the same operating point parameters (head and capacity). In the past, turbines and pumps coupled to the engine / generator on one (usually vertical) shaft were used. Due to the volumetric flow and head values, Francis type turbines dominated, and for large water heads - Pelton type turbines, rarely for small heads - Kaplan turbine
- Bank-Michell turbines and Archimedes screws (that are not turbines) cooperating with pumping systems.

An additional problem is the need to ensure the minimum required height of water inflow at the pump suction when pumping. In practice, the pump-turbine unit most often works with the inflow, which enables work without cavitation. There is no such risk in the case of turbine operation. Pump-turbine machines are typically built as single-stage machines. Therefore, the height at which water can be pumped is limited by the rotor outer diameter. The possibility of increasing the height at which water can be pumped out by increasing the rotational speed of the rotating system (resulting from the theory of similarity of the pumps) is limited by the unfavourable influence of rotational speed increase on net positive suction head - NPSH, that is necessary for the system to operate without cavitation. It is possible to increase the head in pumping water by increasing the rotational speed of the rotating assembly, but it is connected with the necessity of ensuring an increasingly higher water level in the suction tank $h_{\text {smax }}$. Negative values of $h_{\text {smax }}$ are interpreted as the necessity to work with the inflow. The maximum suction lift due to the risk of cavitation in the pump is calculated from the formula:

$h_{\text {smax }} \leqslant \frac{p_{d}-p_{v}}{\gamma}-\Sigma \Delta h_{s}-N P S H+\frac{v_{s}^{2}}{2 g}, m$

The NPSH value is specific for each pump and it should be included in the form of a graph in its characteristics provided by the pump manufacturer. It can also be estimated using the empirical formula for centrifugal pumps:

$N P S H=H \cdot 1,216 \cdot 10^{-3} \cdot n_{Q}^{4 / 3}, m$

The ability to operate without cavitation in the pump depends on the shape of its rotor, i.e. changes with the pump kinematic specific speed:

$n_{Q}=n \cdot Q^{1 / 2} \cdot H^{-3 / 4}$

Head $\mathrm{H}$ in the above formulas is determined for one, first stage of the flow system (pumps may have more stages). As specific speed increases, the need to raise the water level in the suction tank appears. Radial rotors have the lowest specific speed values, and then there are diagonal rotors, helicoidal rotors and propeller impellers. The rotor shapes changing with the specific speed increase are shown roughly in Figure 2. The highest, in practice, efficiency obtained by singlestage, single-jet pumps are achieved for the specific speed $n_{Q}=35 \div 60$, which is shown in the diagram presented in the textbook [9].

In practice, the possibility of realizing large heads is limited by the possibility of pumping in pump- 


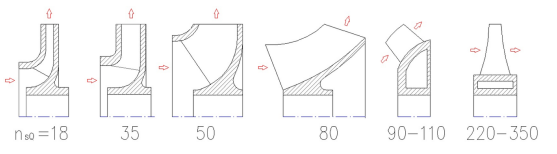

Figure 2: Influence of specific speed value on pump rotor shape, with the direction of flow shown.

turbines. As water needs to be pumped out to a greater height, the rotor outer diameter increases (at a constant rotational speed). The largest machine of this type in Europe is a Francis turbine assembly with a rotor diameter of $4.54 \mathrm{~m}$ (Dlouhé Stráně, Czech Republic). It achieves a $510.7 \mathrm{~m}$ head. It has an axialradial rotor with forward inlet blades. This reduces the overall efficiency of the flow system, but improves the suction properties in case of pump operation.

For the power distribution in the network the following energy storage parameters are important: storage capacity, time of the energy produced availability, the availability of energy on demand in a few minutes, the ability to remotely operate the system, etc. In the case of pumped-storage hydroelectricity, energy availability on demand in a few minutes and enabling generation work remotely are the current standard. The amount of energy that can be collected in the proposed systems depends on the size of the upper and lower water reservoirs and the machines size. Referring to the turbine operation mode, the amount of energy that can be stored is:

$e_{t}=N_{t} \cdot t, W s$

Relating the turbine mode operation time to the water volumetric flow rate, we obtain useful volume of tanks necessary to obtain the desired time of discharge:

$V_{c}=Q \cdot t, m^{3}$

Under hard coal mines conditions, the lower reservoirs, apart from wells, sumps, drains, are all flooded corridors and galleries, which, systematically rinsed, transport particles of dust, quartz, coal, etc. in the water. Hence there is need for periodic cleaning and desalting the tanks at the bottom. The tanks at the top are less contaminated because the water pumped into the pump chamber at the bottom is already pre-treated in the intermediate tanks. Therefore, the total volume of the lower tanks cannot be completely pumped out. The solution to this problem is to build sealed water tanks separated from the environment, or to seal the existing tanks, galleries, corridors, etc.

\section{Research hydroelectric power plant at Coal Mine Jeremenko, Ostrava, Czech Republic.}

The Czech Republic is one of the European leaders in the design and construction of water turbines and their practical application in working facilities: Vltava Cascade, Lipno I and II, Hněvkovice, Kořensko, Orlík, Kamýk, Slapy, Štěchovice I and Vrané, Dlouhé Stráně, Dalešice. The first known water mill in Central Europe operated in the Czech Republic on the Ohře River near Žatec and dates back to the year 718 [10] [11][12]. The research project of pumped-storage power plant operation in the closed hard coal mine Jeremenko (near Ostrava) was launched on July 17, 2015, after a 4.5-year period of preparatory work. The power plant was established with a significant financial contribution of the Czech State (52.4 out of 79 million CZK) and enterprises: FITE a.s. (main contractor, Ing. Pavel Bartoš), Diamo, Reacon and Sigma (Ing. Jiří Šukal) with the scientific support from VSB Technical University of Ostrava (Prof. Ing. Vladimír Slivka, VŠB-TUO) and the Department of Mining Supervision. The existing mine drainage system was used and new Pelton type water turbine at the level of approx. 580 meters below the framework was installed. The computational capacity was $Q=0,14 \frac{\mathrm{m}^{3}}{\mathrm{~s}}$, the rotational speed of the turbine was $n=1500 R P M$. The system was supposed to reach $732 \mathrm{~kW}$ power, but about $680 \mathrm{~kW}$ of electric power (voltage 400V) was obtained. Mine water circulated in the system, saline at a temperature of about 26 degrees. The surface reservoir had a volume of $4000 \mathrm{~m}^{3}$, and the working volume was $3000 \mathrm{~m}^{3}$. The leading pipeline to the turbine had diameter of $300 \mathrm{~mm}$ (Figure.3).

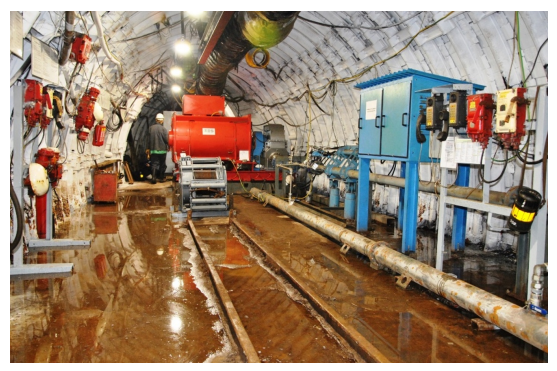

Figure 3: The view of water turbine and generator in pumping chamber [ Ing. Pavel Bartos̄, FITE a.s.]

Turbine and generator controlling was automatic within a few minutes. The system could be turned on and off remotely. The turbine was turned off automatically when the minimum water level in the upper tank was reached. The project was a testing ground for possibilities that enable the Czech Republic to reach the planned energy mix of electricity: $50 \%$ from nuclear power plants, $25 \%$ from RES in 2040 . It was assumed in the research project that the pumpedstorage power plant would work for one year. As a conclusion, the capacity of the target pumped-storage plant, depending on the conditions of the mine, was specified at 5-10 MW and the size of the upper reser- 
Duisburg-Essen are shown, in which the upper reser-

voirs on the area of approx. $20000 \mathrm{~m}^{3}$. In the discussed case, the use of water temperature for heating purposes was also considered, assuming that the pumped water was demineralised. The current total capacity of pumped-storage power plants in the Czech Republic amounts to $1.175 \mathrm{GW}$, producing $1290 \mathrm{GWh}$ in the record year of 2015.

\section{German analyses of the pumped-storage power plants construction in liquidated coal mines}

The current German pumped-storage power plants have potential of approx. $5 \mathrm{GW}$ power and allow for about 20 GWh electric energy production per year [13]. In connection with the decommissioning of nuclear energy and the development of renewable energy sources, in particular PV, this potential was identified as insufficient [13][14]. As part of the project "Storing wind energy by reusing liquidated mines", financed by the Federal Ministry of the Environment, a group of scientists from the Clausthal University of Technology (Clausthal-Zellerfeld, Lower Saxony, Germany) and industry representatives designated 104 underground facilities suitable for pumped-storage power plants. Information on the works carried out has been provided since the beginning of 2010, assuming the target commencement of works on designated post-mining facilities for 2015-2018 [15] [15]. This period was not kept. The use of new locations is expected to double Germany's current energy storage potential. Based on the analyses, it was found that the former metal ore mines would be the most appropriate. Some restrictions were defined for closed hard coal and salt mines: explosive methane, coal dust and quartz dust in the pumped water, water salinity, the possibility of leaching raw materials (salt) and toxic substances from the rock masses. Objects where soft rock would require the construction of expensive reinforcements were excluded. The concept of the installation was presented in the articles [16][17]

The former Pöhl ore mine in Erzgebirge and the Wiemann shaft of the closed Grund ore mine in the Harz Mountains were identified as pilot mines. In a unified system, each power plant is supposed to have $100 \mathrm{MW}$ capacity and water reservoirs enabling the $400 \mathrm{MWh}$ electric energy production per year. A 700 $\mathrm{m}$ head was assumed and the volume of usable underground tunnels and channels was specified. In Figure 4 a proposed aggregate for such target by Voith is presented [18]. The diameter of the largest element that needs to be transported is $5.6 \mathrm{~m}$. The turbine casing and pumps can be segmented. The water turbine efficiency is $91 \%$, the pump efficiency is $90 \%$ and energy storage efficiency is $75 \%$. The cost of setting up one pumped-storage power plant was estimated at EUR 180 million. In the presentation [[19]] the results of the research conducted by the University of voir was also located under the earth's surface. Failure to launch these investments is explained by economic unprofitability, lack of amortization with the current formula and energy prices in Germany. The sale of energy alone is insufficient; the facility would have to be covered by a permanent subsidy system.

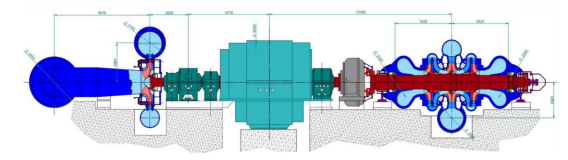

Figure 4: Water turbine, motor/generator and twostage, double-suction pump assembly dedicated to work in mine. Power generated - $90 \mathrm{MW}$. Source: Voith AG [2]

On 20th and 21st November 2014, at the 2nd EFZN (Goslar) pumping magazines conference, engineer Stephan Hloucal presented the work of a pilot project for the Am Petersenschacht hard coal mine pumped-storage power plant (Sondershausen, Germany) [20][21]. The Pelton turbine system cooperated with the mine's drainage pumps. The existing system lower water reservoirs capacity was $10 \mathrm{k} \mathrm{m}^{3}$ of water. The difference in levels between upper and lower reservoirs exceeded $700 \mathrm{~m}$. The power of hydraulic machines that could be applied in was determined in the range of 1.5-1.8 MW. The flow of $\mathrm{Q}=$ 250 I / s was realized with four $200 \mathrm{~mm}$ diameter pipelines.

\section{Concepts of pumped-storage power plants in liquidated underground mines in Poland}

Nowadays, there are 20 hard coal mines in Poland. In most of the closed mines, the underground infrastructure has been devastated by flooding, which makes the possibility of returning to the closed excavations economically unprofitable. In the current conditions of the energy market in Poland, there is still large advantage of controllable energy sources over changeable ones. It is economically unprofitable to build new pumped-storage power plants and to operate the existing ones. Not without significance is the fact, that the Energy Regulatory Office does not recognize pumped-storage power plants as renewable energy sources. This privilege and the associated financial support are reserved for gravity hydropower plants.

Economic analyses and profitability evaluation of the pumped-storage power plant in the Upper Silesia hard coal mine, which has been closed since December 1 , 2016, were conducted assuming the cost of building the power plant from external funds and further han- 


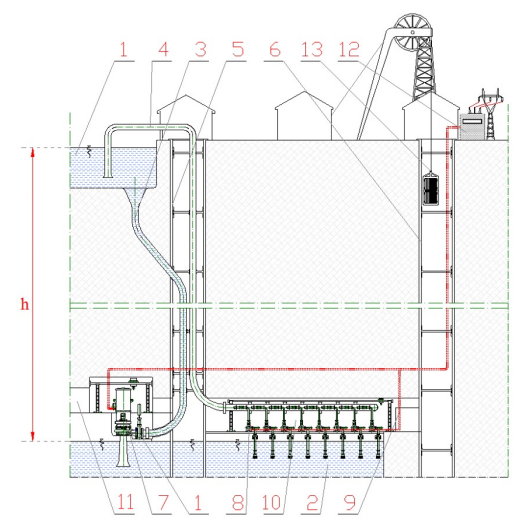

Figure 5: Diagram of a pumped-storage power plant in the infrastructure of a liquidated hard coal mine with a system of parallel pumps. 1-upper tank 2lower tank 3-rainfall channel 4- discharge channel 5water flow shaft 6-transport shaft 7-water turbine 8centrifugal pumps 9-power lines 10-pump chamber 11transport walkway 12 -voltage transformation station 13-transport cage.

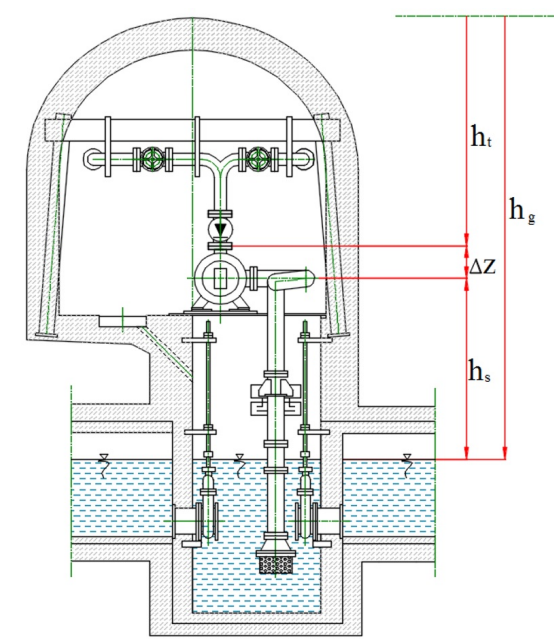

Figure 6: Diagram of the multi-stage, main drainage centrifugal pumps installation.

dover of the new facility to the special purpose vehicle. Depending on the assumed models of predicting energy prices changes in the future, the profit from such activity without the burden of making the investment oscillated around zero, which is consistent with world data [22]. Currently, large hydropower plants in Poland are similarly balancing on the verge of profitability. For them, the existing mechanisms of 15-year financial support - green certificates - are expiring. This system of property rights assigned to certificates of origin for energy from renewable sources, established by the Polish Parliament, entered into force on October 1, 2005. Therefore, one should not be pes- simistic, because the function of energy storage successfully performed in pumped-storage power plants cannot be compared to the cost of energy production.

Energy storage is the domain of technologically highly developed economies. It is designed to stabilize and compensate energy systems in accordance with the principle that the most expensive energy is energy not delivered. It is an inseparable element of nuclear energy. Further development of weather-dependent energy sources will result in great necessity to balance the network. Energy that is not delivered for a short time can lead to damages and costs up to one hundred times the price of energy systematically supplied. Currently, little attention is paid to the possibility of interrupting the continuity of energy supply, optimistically assuming that in the current state of technology this does not happen except in failure situations.

In the recent years of intensive renewable energy sources development, it is possible to avoid the use of existing coal-fired units in case of large load changes, which is accompanied by high emissions of substances harmful to the natural environment. Currently operated coal units have undergone a number of modernizations that have significantly reduced their emissivity. However, there is still only one optimal load point at which emissivity is the lowest with the highest energy efficiency. The load shift means operating away from this optimal point. Such investments are made with significant financial support from the state.

\section{Technical limitations of building a pumped- storage power plant in hard coal mine.}

There are two mutually proportional quantities determining the power that can be obtained from the water flow: efficiency and height. Increasing the power is achieved by increasing the efficiency or the head difference between upper and lower tank. Therefore, it is important to use the maximum potential of the mine and to build the engine room at the lowest possible level. A schematic diagram of such a system is shown in Figure 5. The pump installation is shown in Figure 6. Assuming that one of the mine shafts will be completely covered with water pipelines, it is necessary to use the other shaft for transport, electricity transmission and aeration purposes. In Polish mines, system of at least two shafts is the basic model. One of the shafts that accompany the mine for ventilation can also be used. The area for ventilating in case of pumped-storage power plant will be significantly smaller than in case of mining works.

The personal inspection of machines at their work place involves additional costs, but it gives the possibility of supervision and possible interventions. In the '90s, during the intensive liquidation of deep mines in 
Upper Silesia, the necessity to maintain the existing shaft drainage systems in order to protect the hydrological balance of the region was recognized. A technical solution for shaft drainage without the need to maintain underground infrastructure was looked for, with treating the liquidated mine as large wells. The idea of pumping out mine water from a shaft treated as a well, implemented in one of the mining plants in Czeladź, showed a number of significant disadvantages of this solution. The multi-stage, submersible drainage pump was lowered into the water in the shaft on the flange-connected pipeline elements. The next parts of the pipeline are assembled while the pump is gradually lowered. In the case of removing the pump for inspection or renovation, the heavy pump swung on a long pipeline and hit the shaft walls caused pump casing devastation (January 2008). In this case, the pump was damaged, but it was possible to pull it to the surface and renovate it. In a similar attempt carried out in the shaft of the Dąbrowa Górnicza mine, a submersible pump broke off and fell down the shaft. The weight of the pump and the engine exceeded 3 tons. Due to the considerable depth of the shaft and over 100 meters of water at its bottom, no attempts were made to recover the pump. Additionally, pumping mine water, which is naturally highly mineralized, caused the deposition of minerals on the flow elements. The corrosive action of the salts contained in the mine water was also unfavourable. The system, which was supposed to be maintenance-free, required frequent disassembly which generated high costs. Figure 7 shows a photo of the damaged multi-stage submersible pump casing.

An additional limitation of water pumping in the mine is the need to provide a second reserve pipeline, which in the normal operation can act as fire protection. In main drainage systems of mines, in which the pumping technology has been brought to a high level of reliability and safety of people's work, there are a lot of limitations and requirements characteristic of mining work. They cause the additional financial burdens in case of pumped-storage power plant operation. There are no exemptions and simplifications in Polish legislation for using the former mine infrastructure for energy purposes. The possible development of this industry must be accompanied by a series of simplifying legislative changes taking into account the new role of shafts, water reservoirs, machine chambers, human service, etc.

Along with the lowering of mine galleries, the risk of methane appearance and its concentration identified as endangered increases. Part of this problem can be solved by planning the waterproofing of the lower wa-

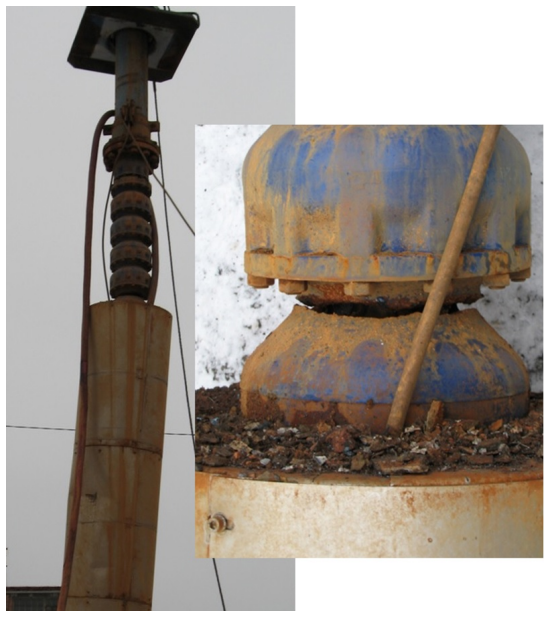

Figure 7: Damaged casing of a submersible drainage system pump used in a liquidated hard coal mine.

ter reservoirs with bituminous masses. In the case of the aforementioned analysis of the construction possibilities in Krupiński coal mine, the lower reservoir was supposed to be in an $8 \mathrm{~km}$ long bitumen-sealed gallery. The gradual flooding of the mine resulted in a significant decrease in the methane release from the rock mass after exceeding the critical depth. Although it is advantageous in terms of safety, it called into question the investment in recovered methane compression system. In the opinion of geologists and builders, the raised doubts about the strength of the lower reservoir with its intensive daily filling and emptying are not a technical problem.

The capacity of the reservoirs depends on the desired water turbine operation time. Due to the fact that the mines in Upper Silesia are located near cities, sometimes even in their centres, the construction of upper water reservoirs in the vicinity of the mine shaft will often be a serious problem. In practice, assuming reservoir depth at the level of 25-30 meters results in its large area. At the same time, the ground under the surface reservoir must be stable. In case of the city of Bytom or area near Sosnowiec city, it is difficult to obtain because the areas of pre-war mines flooded during the war are not precisely identified.

Another limitation is the possibility of transporting and installing hydraulic machines: turbines and pumps at the place of their target work - the engine room. The currently operated machines (main drainage system pumps) have dimensions that enable their transport to the surface after disassembling them from engines and their work stations. It is required in order to carry out the planned repairs and measurements of flow characteristics at the pump manufacturer testing station. Shafts in Polish mines were built with a 
practically capable of it. They can design centrifugal

diameter of up to $9 \mathrm{~m}$. Due to the construction of the shaft, which enables its inspection and renovation works, the actual dimensions of the window (usually rectangular) in which machine elements can be transported, do not exceed $4.6 \mathrm{~m}$ in length. Shafts that were not used were smaller in diameter. The mines in Upper Silesia were built according to the identified coal deposits lying at various depths.

In an unfavourable case, high-energy, valuable coal was deposited in layers tilted at an angle of 30 degrees (liquidated Kazimierz-Juliusz coal mine in Sosnowiec). After the deposit was exploited at one depth, the lower layers were exploited. Successive levels were created depending on the identified coal layers. The desire to exploit coking coal deposits in this mine forced the necessity of systematic water discharge from the area of the upper flooded historic mine. The forecast elevation difference was about 150 meters and the estimated water resources capacity was about 2-3 million $\mathrm{m}^{3}$. Therefore water turbine installation at the outlet of the discharge pipeline was planned. Wrong outflow valve selection (too low pressure) and, consequently, a serious failure led to an intensive, continuous inflow of water to the lower levels of the mine. There was a need for main continuous drainage. This event excluded the possibility of implementing an interesting concept of turbine operation in hard coal mine.

In many Polish mines, the levels close to the ground surface can be reached by truck via transport corridors from the surface. This is practically impossible for levels below $600 \mathrm{~m}$. It is beneficial to install hydraulic machines at the deepest mine levels. However, in this case the machines have to be transported in whole or in part using the shaft, taking into account its geometric limitations.

\section{Possibilities of building mine shafts and hy- draulic machines in Poland}

There are currently two companies in Poland that successfully build mine shafts. The first is JSW S.A. Przedsiębiorstwo Budowy Szybów. It is currently building the "Grzegorz" shaft at Zakład Górniczy "Sobieski". The shaft has diameter of over 9 meters and is more than 700 meters deep. The second company is Przedsiębiorstwo Budowy Kopalń, a subsidiary of KGHM S.A. This year, it completed the construction of the deepest shaft in Poland: GG-1 (1351 m) in Kwielice, in the Grębocice commune. The shaft has a diameter of $7.5 \mathrm{~m}$. In both cases, the sinking technique is carried out after freezing the sinking area to a temperature close to -28 degrees, which significantly reduces water hazards during construction.

As far as centrifugal pump production is concerned, there are several business entities in Poland that are pump for given parameters with ensuring high efficiency. Apart from research centres, there are also national design offices for centrifugal pumps. There is one economic entity dominating the market, based in Zabrze, which is able to design, manufacture and test the necessary pumps. In Poland, complete sets of pump elements can be manufactured, the documentation and assembly of which take place outside our country, e.g. a factory based in Gliwice.

There are no large water turbines manufacturers on the domestic market. A possible dedicated turbine can be made designed on the practical knowledge of the still functioning scientific community of water turbine engineers in cooperation with contractors available on the market. The actual problem that has emerged in recent years is the long, several-month-long process of numerical testing that is necessary for a new hydraulic machine design. The result of this work, however, is excellent in practice.

\section{Separation of pumping and generation func-} tions.

A simplified analysis of a hypothetical pumping system operation was carried out, based on: hydraulic machines availability on the Polish market, their actual dimensions and suction limitation connected with the rotational speed increase. The results are shown in Figure 5. It was assumed that the elevation head is $780 \mathrm{~m}$ and there the available shaft has window dimensions of $3.6 \times 4.6 \mathrm{~m}$. The diameters and type of pipelines are not imposed. Due to the individual design and construction of the water turbine, it was assumed that it would be possible to transport its elements and assemble them at the target site. In first variant, the use of a number of centrifugal pumps available on the market was assumed. In second variant dimensions of one pump, which would replace a number of centrifugal pumps, were determined. Size of the tanks ensured 6 hours of generation work.

The first approach assumed the variant of minimum investment, i.e. the purchase of a water turbine for the given parameters and the use of pumps available on the market, well-known to users. The point of optimal pump operation, with the highest efficiency of the machine, is $500 \mathrm{~m}^{3} / \mathrm{h}$. The number of pump stages used allows pumping to the elevation of 800 $\mathrm{m}$ with the power consumption at the pump shaft close to $1300 \mathrm{~kW}$ (Figure 9). The characteristic of the maximum suction lift of the pump allows locating the suction section of the system at elevation of up to 7 meters without fear of cavitation.

Connecting pumps in parallel ensures high capacity. Such operation is limited by the point of intersec- 


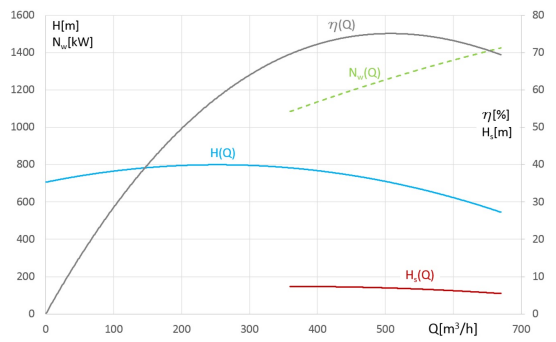

Figure 8: OW-250 pump performance curves.

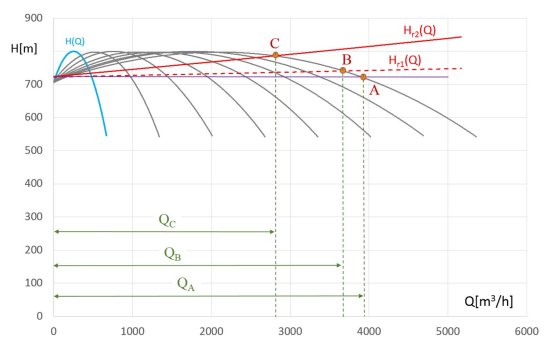

Figure 9: Parallel pump operation. Pumps and pipeline characteristics.

tion of pump curve and system curve, shown in Figure9. The characteristics of a 10-stage centrifugal pump were summed for 8 cooperating pumps connected to a common collector. When system operates at low flow velocities, head losses, which increase with the square of the velocity, are small $\left(H_{r 1}(Q)\right)$. The capacity $H_{B}$ is slightly lower than the theoretical capacity $H_{A}$. In case of an increase in losses, e.g. due to the minerals deposition on the pipeline walls and reduction of the pipeline useful diameter, the system curve slope changes to the curve $H_{r 2}(Q)$ and capacity to $Q_{C}$. Reducing water velocity, i.e. reducing head losses, shifts the point of intersection to the right again, increasing capacity. Water velocity at discharge line recommended in the literature is in the range of $v_{t}=2 \div 2,5 \frac{\mathrm{m}}{\mathrm{s}}$

\section{High capacity and high head pump design for analysis}

In case of building a pumping system with one centrifugal pump for a given head and capacity with a power close to $100 \mathrm{MW}$ and satisfactory suction abilities, a dedicated centrifugal pump should be designed and built. The Voith pump proposal presented in Figure 4 has a technologically demanding two-stream, two-stage system. It has the advantage of minimizing the axial force system. For similar two-stream, singlestage flow systems, the highest maximum pump efficiency in Poland was experimentally achieved. This efficiency was $92 \%$. In order to properly manufacture such an efficient machine, with the current potential of experienced designers and CFD experts, a time of two years should be assumed for building the proper pump. In view of the presented attempts to adapt the infrastructure of a liquidated hard coal mine to the construction of a pumped-storage power plant, with elevation head of approx. $700 \mathrm{~m}$, representative of the KWK in Upper Silesia and the power of a single pump of 12-24 MW, it is possible to carry out design calculations for the pump rotor based on the verified algorithms available in the literature [23][24] [25]. The power value results from head and capacity assumptions. Head is assumed to be $800 \mathrm{~m}$,capacity value arises from the velocity assumptions $v=2,5 \frac{\mathrm{m}}{\mathrm{s}}$ and one or two pipelines diameter close to $1 \mathrm{~m}$.

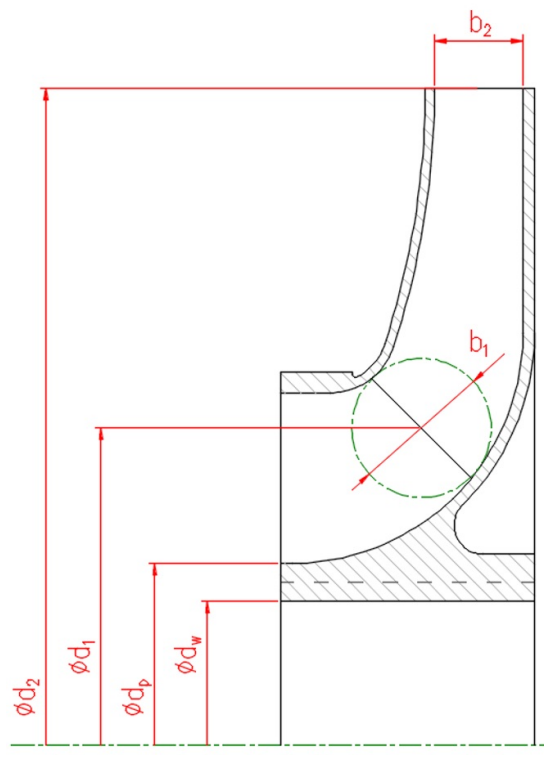

Figure 10: Centrifugal pump rotor main dimensions.

The dimensions of the pump rotor (Figure 10) determine to a large extent the dimensions of pump casing and determine its suitability for use in coal mine drainage system. The basic parameters and dimensions of the rotors presented in the table (Figure 11) take into account different concepts of pumping. All presented concepts include one centrifugal pump and one turbine shown in the hard coal mine infrastructure scheme in Figure 12. In the first case, it is a multistage pump rotor with the lowest capacity, often assumed for coal mine drainage system pumps. The rotational speed of pump is equal to $n=1450 \mathrm{rpm}$. In the second case, the rotor of a multistage pump with a higher capacity, for which the rotational speed was determined in order to facilitate pump suction process. The third case includes a rotor which obtains a head of $400 \mathrm{~m}$ at rotational speed $\mathrm{n}=1450$ $\mathrm{rpm}$. A pump with two rotors of this type will ensure the desired head of $800 \mathrm{~m}$. The presented calculation results give an overview of main dimensions of a cen- 
relieving disc. The wear of the disc and its necessary

trifugal pump, which would operate in a system with an elevation head exceeding 700 meters.

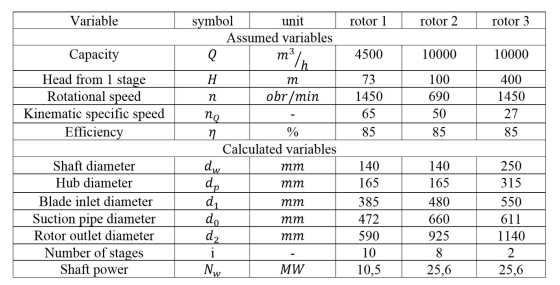

Figure 11: Dimensions of exemplary centrifugal pump rotors.

Pump casing dimension results from the given rotor dimensions, but also from stator blades dimensions, suction and discharge channels, bearings and axial force transmission system that have to be included. The multistage pump construction is determined by the necessity to keep the dimensions at the level that enable transport of the machine to the place of its target operation and by demanded suction abilities. The head value adopted in the project is in practice multiplied by the number of stages to reach the required head at which water should be pumped. Operating with oversized pump is connected with energy losses so after pump installation, its initial operation and measurements, the geometry of the last rotor can be corrected; usually the rotor outlet diameter is reduced.

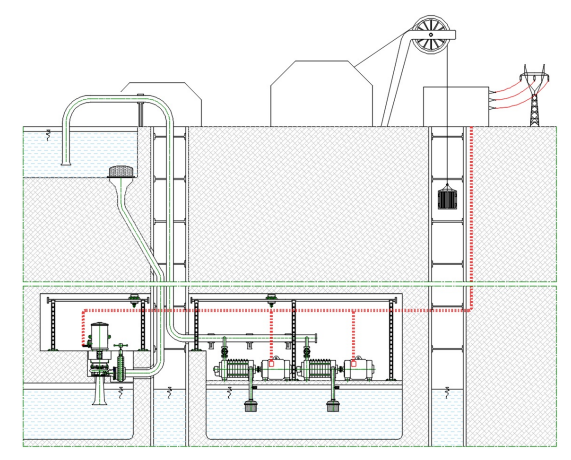

Figure 12: Diagram of pumped-storage power plant in a liquidated coal mine infrastructure, system with one pump and one turbine. 1-upper tank 2-lower tank 3-rainfall channel 4-discharge channel 5- water flow shaft 6-transport shaft 7-water turbine 8centrifugal pump 9-power lines 10 pump chamber 11transport walkway 12-voltage transformation station 13-transport cage.

A significant problem when designing the entire pump is the choice of the method of balancing the axial force generated during operation. The pump most often used in Polish mines has the so-called axial force overhaul was the most common reason for the scheduled shutdown of the pump. In mines with heavy water pollution, especially with coal dust and quartz particles, the scheduled operating time of the pump is approx. 1500-2000 hours. In an extremely unfavourable case observed in hard coal mine "Wieczorek", after the action of filling the liquidated galleries with dust from the power plant, the inter-renovation time was 200 hours of pump operation. The axial force for 10-stage pumps, in case of rotors with the same arrangement on the shaft, can be over 20 tons. The existing solutions for replacing the disc with large rolling bearings or plain bearings are very expensive. In the past, there were attempts to use them in a prototype drainage pump, but the price of bearings was half the price of the entire pump.

The presented considerations should be widened with an analysis of the hydraulic shock (water hammer) occurrence possibility in the designed relatively long channels (the length is related to the diameter of the pipeline). Hydraulic shock is strongly dependent on the speed of closing the flow when switching on and off hydraulic machines. When the flow is suddenly closed the pressure rises several times over the nominal pumping pressure. Assuming the possibility of a dangerous power outage and suddenly pump or electric driven valves shutdown, one of the numerous technical solutions should be used in the design to prevent negative effects: water aeration, pressure reducers, compensators, etc.

\section{Summary}

The conducted research and analyses clearly show that it is technically feasible to carry out the task of accumulating energy in a pumped-storage power plant in a closed hard coal mine. The experience gained in the Czech Republic and in Germany can be a starting point for the construction of a pilot facility in Poland. The current, high efficiency of large pumpedstorage power plants (up to $75 \%$ ), their reliability and operational safety constitute their monopoly in the world's energy storage resources ( $96 \%$ of the total storage potential). Due to the current limitations of the mine shafts dimensions and the possibility of machines transporting, the capacity of one facility will not exceed $25 \mathrm{MW}$ without major investments in the mine infrastructure. It is currently insufficient for system operators in Poland. Power of $90 \mathrm{MW}$ could be achieved when interfering with mine shafts, galleries and chambers. Further challenges of implementing pumped-storage power plant in closed coal mine infrastructure include high investment costs of such facilities, which are practically non-amortising, and the lack of appropriate legal regulations and support sys- 
11.SLÁČALA, P. (2015 [cit. 2021-02-05]) Environ-

tem, e.g. the lack of recognition of the facilities currently in operation as renewable energy. The lack of decisions regarding large energy accumulators is also related to the lack of energy model choice: distributed energy model or centralized energy model. Further development of weather-dependent energy sources, a periodic increase in energy prices and the likely phenomenon of energy not supplied will force in the future the construction of storage facilities stabilizing the power system. The search and development of new methods of electric energy accumulation should be carried out in relation to the already obtained efficiencies of known and used methods.

\section{References}

1. (2015) Overview of current development in electrical energy storage technologies and the application potential in power system operation. Applied Energy, 137.

2.Borden, E. (2014) Expert view on the role of energy storage for the German energiewende in final report Alexander vo Humbold foundation German Chancellor Fellowship. German Institute for Economic Resarch.

3.ŁukaszBartela (2020) A hybrid energy storage system using compressed air and hydrogen as the energy carrier. Energy, 196.

4.Steller, J. (2013) Hydropower and its development. Acta Energetica, 3/16.

5.Chi-Jen Yang, R.B.J. (2011) Opportunities and barriers to pumped-hydro energy storage in the United States. Renewable and Sustainable Energy Reviews, 15.

6. (2016) Development and Implications of a Predictive Cost Methodology for Modular Pumped Storage Hydropower (m-PSH) Projects in the United States, Oak Ridge National Labolatory.

7.Weber, B.S.C. (2016) Optimal operation of pumped-hydro storage plants with continuous timevarying power prices. European Journal of Operational Research, 252.

8.Uddin, N. (2003) Preliminary design of an underground reservoir for pumped storage. Geotechnical and Geological Engineering, 21.

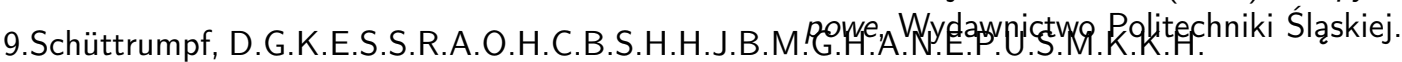

(2014) Pumpspeicherkraftwerke, Springer Vieweg,

Wiesbaden.

10.Muzikova, M. Moznosti vyuziti dulnich del jako precerpavaci elektrarny. mentální aspekty vodních elektráren v České republice [online].

\section{Lukeš, D. (2007) PŘEČERPÁVACÍ VODNÍ} ELEKTRÁRNY

13. Madlener, R., and Specht, J.M. (2020) An Exploratory Economic Analysis of Underground Pumped-Storage Hydro Power Plants in Abandoned Deep Coal Mines. Energies, 13 (21).

14. Havranek, F. (2012) Pumpspeicherkraftwerke als zentraler Baustein der Energiewende: Eine Wirtschaftlichkeitsanalyse für das deutsche und österreichische Marktgebiet.

15.Luick, H., Niemann, A., Perau, E., and Schreiber, U. (2012) Coalmines as Underground Pumped Storage Power Plants (UPP) - A Contribution to a Sustainable Energy Supply?. 14, 4205-.

16.H.-P. Beck, M.S. (2011) Windenergiespeicherung durch Nachnutzung stillgelegter Bergwerke. EnergieForschungszentrum Niedersachsen.

17.Steffen, B. (2011) Prospects for pumped-hydro storage in Germany, University of Duisburg-Essen.

18. (2011) Maschinentechnische Aspekte. Voith AG \& Institut für Maschinenwesen (IMW).

19.Niemann, A. (2012) Main concepts for construction of pump storage system using coal mining infrastructures.

20.Wortberg, R.A.M.A.N.T. (2015) Underground Pumped-Storage Hydroelectricity Using Existing Coal Mining Infrastructure. Proceedings of the 36th IAHR World Congress.

21.Hloucal, S. (2014) Untertägige Pumpspeicherkraftwerke (PSWu) im Kali- bzw. Salzbergbau zur Verbesserung der Netzintegration von Erneuerbaren Energien. Vortrag anlässlich der 2. Pumpspeichertagung des EFZN, 20. \& 21, Goslar.

22. Snapshots of Pumped-Storage Projects" Hydro Review.

23.Adam Tadeusz Troskolański, S.Ł. (1973) Pompy Wirowe, Wydawnictwo Naukowo Techniczne.

24.Jędral, W. (2014) Pompy Wirowe, Oficyna Wydawnicza Politechniki Warszawskie.

25.Andrzej Korczak, J.R. (1997) Pompy i układy pom- 